\title{
Reactive Oxygen Species and Cellular Interactions Between Mycosphaerella fijiensis and Banana
}

\author{
Maria de Jesus B. Cavalcante • Jacques Escoute • Jean Paul Madeira • \\ Rocio E. Romero • Michel R. Nicole • Luis C. Oliveira • Chantal Hamelin • \\ Marc Lartaud • Jean L. Verdeil
}

Received: 2 June 2010 / Accepted: 22 February 2011 /Published online: 19 March 2011

(C) Springer Science+Business Media, LLC 2011

\begin{abstract}
Globally, the banana plant (Musa spp) is the fourth most important crop after rice, wheat and corn (based on production in tons). It is cultivated in more than 100 tropical and subtropical countries, mainly by small producers and is a fundamental food source for millions of people. Black leaf streak disease (BLSD), caused by Mycosphaerella fijiensis Morelet (sexual phase) or Paracercospora fijiensis (Morelet) Deighton (asexual phase), is the main disease affecting the world's banana culture. This disease has a wide geographical distribution accounting for losses exceeding $50 \%$ of global banana
\end{abstract}

Communicated by: Paul Moore

M. de Jesus B. Cavalcante $\cdot$ J. Escoute $\cdot$ J. P. Madeira

R. E. Romero $\cdot$ M. R. Nicole $\cdot$ L. C. Oliveira $\cdot$ C. Hamelin

M. Lartaud J. L. Verdeil

Histology and Plant Cell Imaging Laboratory,

CIRAD TA A 96/02 Avenue Agropolis,

34398 Montpellier, France

M. de Jesus B. Cavalcante $\cdot$ J. Escoute $(\bowtie) \cdot J$. P. Madeira

R. E. Romero - C. Hamelin · M. Lartaud • J. L. Verdeil

Centre de Coopération Internationale en Recherche Agronomique

pour le Développement Unité Mixte de Recherche Département

d'Amélioration des plantes-Plateforme,

d'Histocytologie et d'imagerie végétale CIRAD,

BP cedex 05, 34398 Montpellier, France

e-mail:maju@cpafac.embrapa.br

M. R. Nicole

Institut de Recherche pour le Développement,

Unité Mixte de Recherche Résistance des Plantes aux

Bioagresseurs,

IRD-CIRAD-UM2, BP 64501, 34394 Montpellier, France

M. de Jesus B. Cavalcante $\cdot$ L. C. Oliveira

Embrapa Acre,

CP 321 BR 364 Km 14,

Rio Branco, Acre, Brazil production. We conducted a comparative histocytological study on the kinetics of the infection process using three banana genotypes with phenotypes that differ in resistance to BLSD: Grand Naine (Susceptible), Pisang Madu (Partially Resistant) and Calcutta 4 (Resistant). Experiments were conducted under controlled conditions with the objective of characterizing the cellular interaction processes between $M$. fijiensis and Musa acuminata. Conidia germination occurred 24 hours after inoculation. Germination rates were high (97\%) and there were no significant differences between the three genotypes $(P>0.147)$. The Peroxidase enzyme and $\mathrm{H}_{2} \mathrm{O}_{2}$ were associated with a hypersensitivity-like reaction in the resistant genotype Calcutta 4, indicating a possible role of the enzyme or its product as defense mechanisms against M. fijiensis in banana plants.

Keywords Musa acuminata Mycospaherella fijiensis . Banana black leaf streak disease (BLSD) · Histology · Hydrogen peroxide $\cdot$ Peroxidase $\cdot$ Defence mechanisms

\section{Introduction}

Black leaf streak disease (BLSD), caused by the fungus Mycosphaerella fijiensis Morelet (sexual phase) or Pseudocercospora fijiensis (Morelet) Deighton (asexual phase), is the primary disease affecting worldwide banana production (Marín et al. 2003), and is responsible for more than $50 \%$ of crop losses in productions areas worldwide (Mourichon et al. 1997). The pathogen infects several species in the genus Musa including banana and plantain (Fullerton 1994). Control measures currently rely predominantly on multiple fungicide applications (up to 52 pulverizations per year) with high cost and damaging environmental effects (Marín et al. 2003).The use of 
resistant varieties, however, is one of the more effective alternatives for disease control (Silva et al. 2001).

M. fijiensis is a hemibiotrophic fungus which shows a high level of genetic diversity (Carlier et al. 1996; Hayden et al. 2003), and according to field observations, may be virulent or avirulent (Fouré et al. 1990). Incompatibility, which occurs in resistant genotypes, is characterized by arresting the fungus developmental cycle during the early stages of infection. In contrast, compatible reactions result in complete development of the infectious cycle until the necrotic stage of the disease can be observed in infected plants showing visible sexual and asexual sporulation of the fungus (El Hadrami 2000).

Plants may use different natural defense strategies against various pathogens including non-host resistance, which is effective against several pathogens, and gene-for-gene resistance, where the plant is resistant to one or a few pathogen races (Kiraly et al. 2007). Resistance specificity is generally associated with the hypersensitivity response (HR), which is characterized by formation of small necrotic lesions at infected sites where the pathogen is confined or even killed (Shirasu and Schulze-Lefert 2000).

In most pathosystems, one of the first plant cell reactions in response to pathogen attack is the accumulation of reactive oxygen species (ROS) such as $\mathrm{H}_{2} \mathrm{O}_{2}, \mathrm{O}_{2}^{-}$and $\mathrm{OH}^{-}$(oxidative burst) (Wang et al. 2007). Rapid ROS production is induced by pathogen attack and leads to decay of plant tissue. Several authors suggest that, after pathogen recognition, ROS could play an important role in the inhibition of infection (Hückelhoven and Kogel 2003), leading to a HR (Resende et al. 2003).

Plant peroxidases have been correlated with a defense against numerous pathogens (Bolwell et al. 1998). They constitute part of the ROS early defense response. They are either involved in ROS generation (Mika et al. 2004) or implicated in ROS detoxication as part of the antioxidant complex mobilized by the plant (Hiraga et al. 2001).

The cellular level interaction between M.fijiensis and Musa acuminata is currently poorly documented (Beveraggi et al. 1995; Beveraggi 1992). Based on chromatographic analyses, Beveraggi and colleagues (Beveraggi et al. 1995; Beveraggi 1992) hypothesize that a constitutive phenolic-like compound may be related with the plant resistance. Other authors report the presence of newly synthesized phytoalexins, phytotoxins that could block fungal development, in the resistant plant (Hoss et al. 2000). Therefore, this complex pathosystem needs to be more thoroughly investigated. The present study was undertaken to better elucidate $M$. acuminata cellular defense mechanisms through a detailed comparative histological study of infection using three genotypes of international reference: Grande Naine (Susceptible -S), Pisang Madu (Partially Resistant-PR) and Calcutta 4
(Resistant-R) (Jones 2000). The objective was to identify the presence of free radicals and peroxidase enzyme activity during the infection period between $M$. fijiensis and the three reference genotypes of $M$. acuminate known to differ in degree of susceptibility to the pathogen.

\section{Results}

Germination and Fungal Infection on Leaf Tissues

Ninety-seven percent of $M$. fijiensis conidia germinated $24 \mathrm{~h}$ after inoculation with no significant difference between the three genotypes $(P>0.147)$. The germ tubes demonstrated branching growth. The mycelium seemed to spread randomly, with no orientation towards specific sites on the leaf surface and invaded leaf segments beginning 5 DAI (days after inoculation) by penetrating between the stomatal guard cells and growing inside the stomatal cavity. Sometimes, stomatopodia, adhered to the stomata, apparently facilitating penetration into the leaf.

Before 5 DAI, none of the observations on phenolics, $\mathrm{H}_{2} \mathrm{O}_{2}$ and peroxidase activity were significantly different from 0 DAI or the control (for $\mathrm{H}_{2} \mathrm{O}_{2}$ and peroxidase activity a very faint constitutive reaction was present on the whole leaf). Kinetics started at 5 DAI.

Three weeks after inoculation, significant differences in the percentage of infected stomata appeared between the three genotypes $(11 \%$ for Grande Naine $(\mathrm{S}), 4.8 \%$ for Pisang Madu (PR) and $0.95 \%$ for Calcutta 4 (R)) (Fig. 1).

An ANOVA test indicated significant differences in the time course of infection between the tested genotypes $(P<0.001)$. The angular regression coefficient for Grande

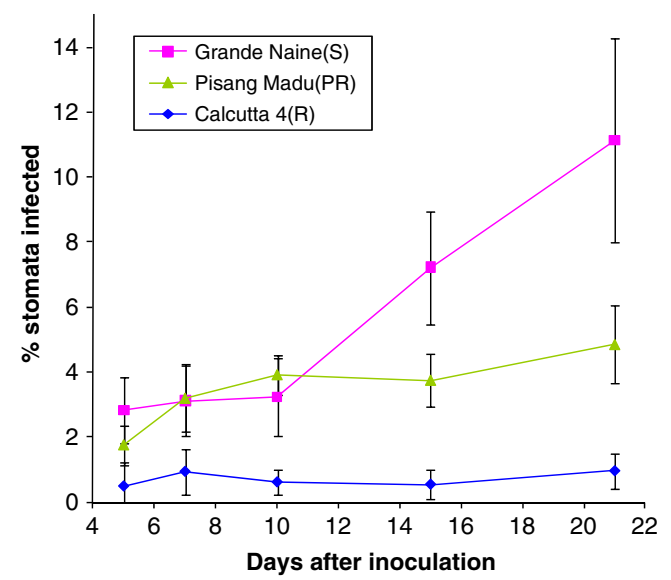

Fig. 1 Accumulative percentage of stomata infection by M. fijiensis over 21 days after inoculation in banana genotypes Grande Naine (Susceptible) (S), Pisang Madu (Partially Resistant) (PR) and Calcutta 4 (Resistant) (R). Percentages were calculated from 373, 591 and 934 observed stomata for Grande Naine, Pisang Madu and Calcutta 4, respectively 
Naine (S) $(b=0.1052)$ was higher $(P<0.05)$ than that of Pisang Madu (PR) $(b=0.0352)$ and was a function of time. At the early stage of the infection, no difference could be detected between the 2 genotypes. For the Calcutta 4 (R) genotype the percentage of infected stomata was always significantly lowest $(P<0.05)$ and did not vary with time $(P>0.29)$ (Fig. 1).

A comparative histological study was undertaken to better understand the time course of host-pathogen interaction. At 10 DAI, the three genotypes were observed under the light microscope to observe that infected stomata were associated with necrotic brown lesions (Fig. 2a, d, g). Cells adjacent to pathogen infection cells and the cells surrounding the infection sites displayed a decrease in red fluorescence under blue excitation light, indicating of loss of chlorophyll leading to leaf chlorosis (Fig. 2c, f and i). Observations under UV light (Fig. 2b, e and h) showed a decrease in cell wall autofluorescence (seen as a darker area around the necrotic lesion), suggesting an apparent cell wall modification as compared to non-infected sites
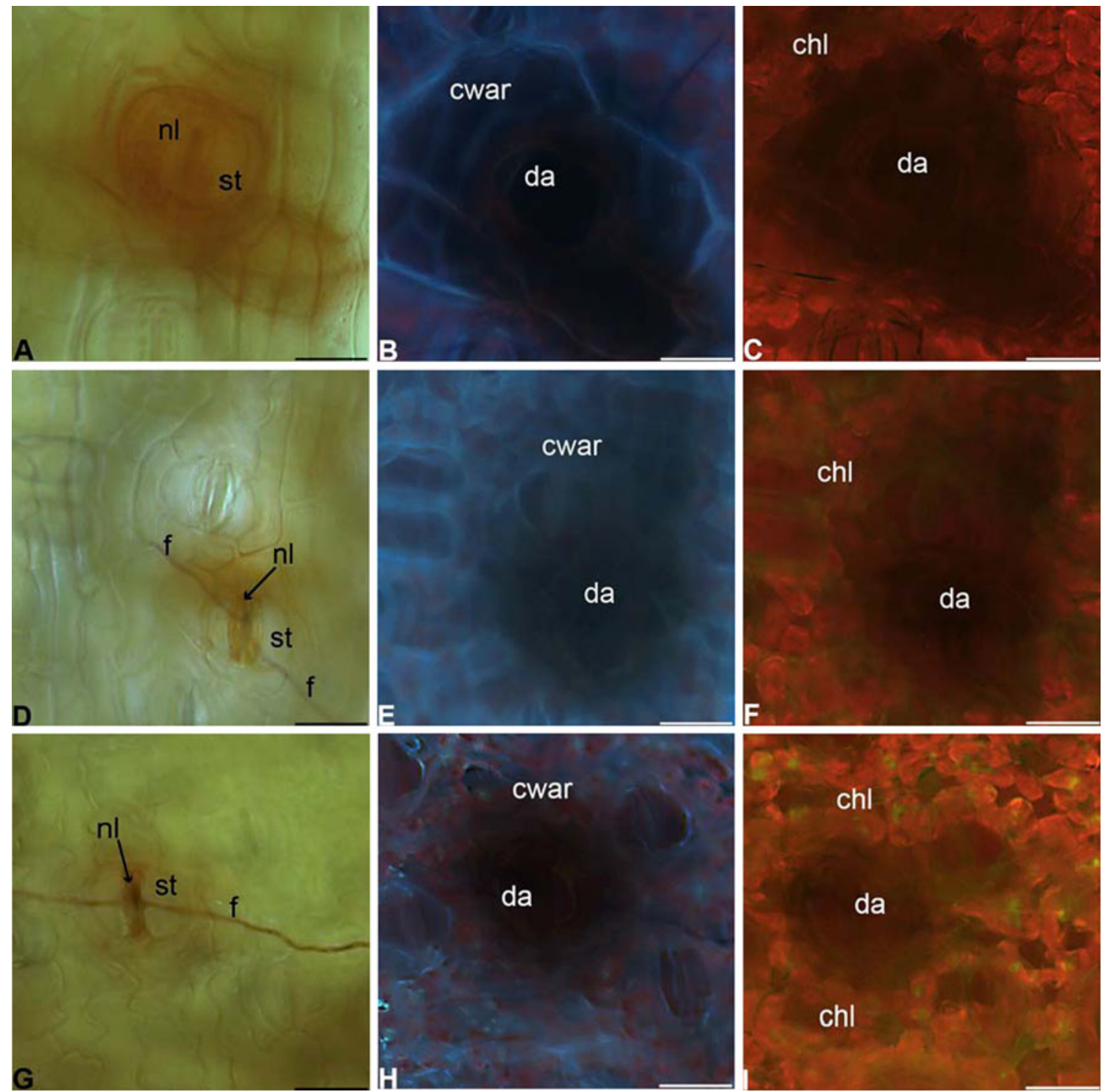

Fig. 2 Alteration of infected tissues "in vivo" 10 day after inoculation. Mycelium close to stomata of Grande Naine genotype (S) leaves stained with methyl blue and photographed under light microscopy (a). No autofluorescence was seen in the infected areas when observed under UV light (b). Under blue fluorescence microscopy, the absence of the red color indicated possible loss of chlorophyll in the infected cells (c). Mycelium close to stomata in Pisang Madu genotype (PR) leaves stained with methyl blue and observed under light Microscopy (d). A decrease in the autofluor- escence of walls from infected cells seen under UV light (e). Under blue fluorescence microscopy, the absence of the red color indicated possible chlorosis of infected cells (f). Mycelium in Calcutta 4 (R) leaves stained with methyl blue under light microscopy (g). Similar observations were made under UV light (h) and blue light (i). (Bar= $22 \mu \mathrm{m})$. cwar: cell wall autofluorescence reduction; chl: chlorosis; da: dark area; f: fungal mycelium; nl: necrotic lesion; st: stomata. UV (Filter A; LEICA BP 340-380/LP 425). Blue (Filter I3; LEICA BP 450-490/LP 520) 

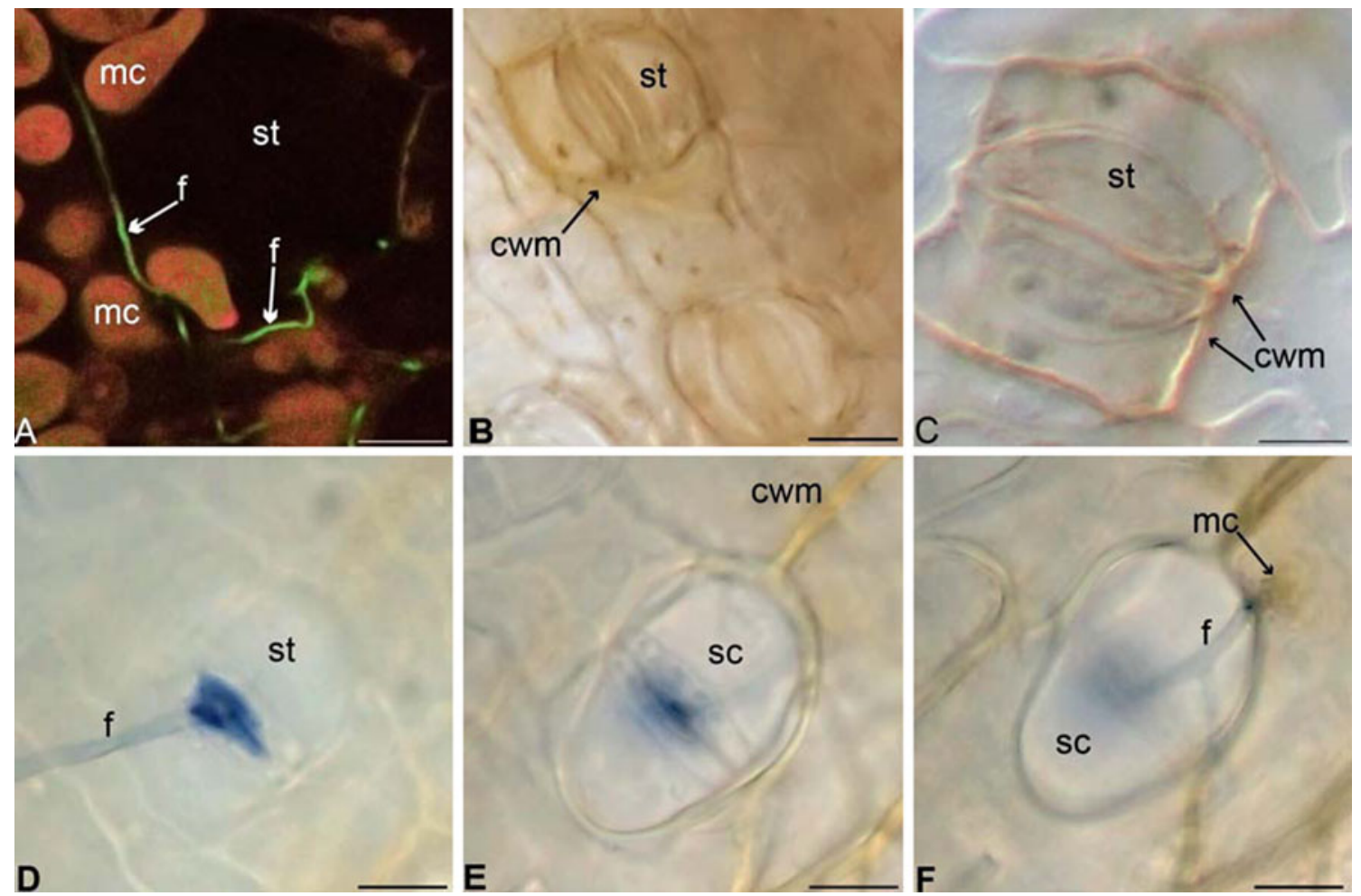

Fig. 3 Fungal germination and infection of leaf tissues. (a) Grande Naine genotype (S): leaf portion fixed, bleached with ethanol/ chloroform and stained with methyl blue. Observed by spectral deconvolution (Zeiss 510 meta). Intercellular localization of the mycelium in the mesophyll; Wall modification of (b) Pisang Madu (PR) and (c) Calutta 4 genotypes (R) infected cells; (d,e,f) Portions of

These histological techniques allowed a comparison of the infection response of the three banana genotypes. The size of the necrotic lesion under light microscopy differed: larger (around $50 \mu \mathrm{m}$ ) in Grande Naine (Fig. 2a) than in Pisang Madu and Calcutta $4(20 \mu \mathrm{m})$ (Fig. $2 d$ and g). The large dark area observed under UV and blue light around the necrotic lesions on in the Calcutta 4 and Pisang Madu infected leaves from Calcutta 4 (R) fixed, bleached with ethanol/ chloroform and stained with methyl blue, showing different stages of stomatal penetration (D) and mesophyll tissues. (bar $\mathrm{A}=22 \mu \mathrm{m} ; \mathrm{B}=$ $13,5 \mu \mathrm{m} ; \mathrm{C}=7 \mu \mathrm{m} ; \mathrm{DEF}=10,3 \mu \mathrm{m})$. cwm: cell wall modification; $\mathbf{f}$ : fungal mycelium; mc: mesophyll cell; sc: substomatal cavity; st: stomata

genotypes was more evident than the size of these necrotic areas observed under light microscopy (Fig. 2e, h, f, i). For the genotype Grande Naine the surface of this dark area was nearly equal to the necrotic zone (Fig. 2b, c). The same pattern (Calcutta 4, Pisang Madu) was observed for quenching of the autofluorescence of the cells walls around the dark area (Fig. 2e, h). Chlorosis surrounding the
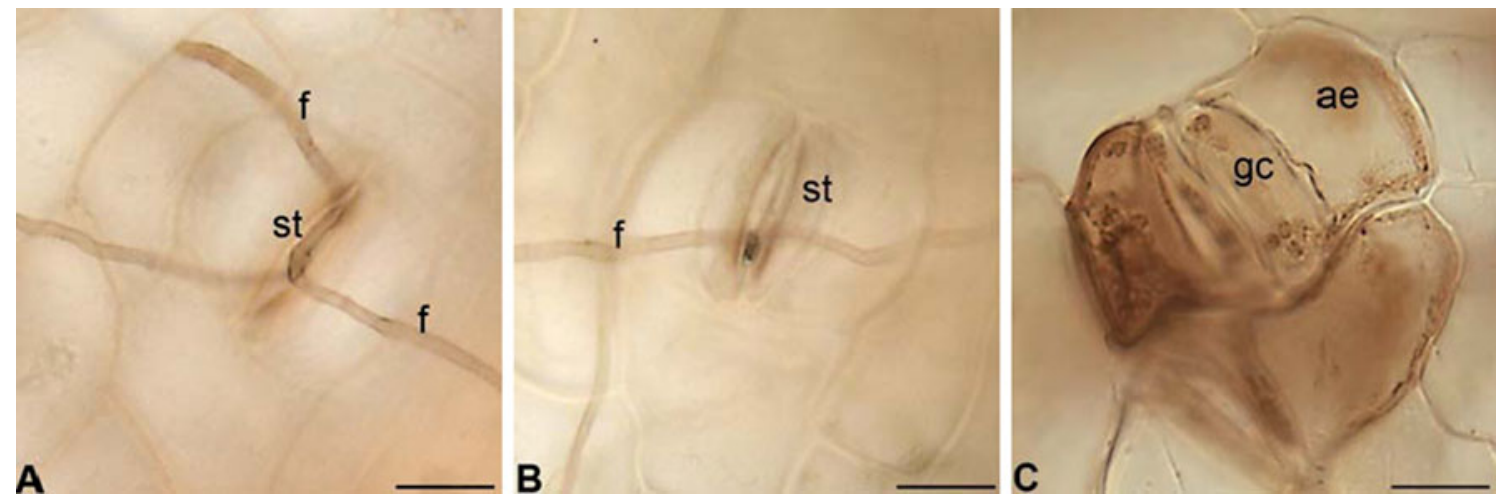

Fig. 4 Histochemical localization 10 day after inoculation following DAB staining. No accumulation of $\mathrm{H}_{2} \mathrm{O}_{2}$ in infected cells from (a) Grande Naine (S) and (b) Pisang Madu (PR) genotypes was observed; (c) In leaves from the Calcutta4 (R) genotype a strong brown staining of stomatal cells was detected, indicating the presence of $\mathrm{H}_{2} \mathrm{O}_{2}$. (bar: $\mathrm{A}, \mathrm{B}=22 \mu \mathrm{m} ; \mathrm{C}=14 \mu \mathrm{m})$. ac: annex cell; gc: guard cell; f: fungal mycelium; st: stomata 


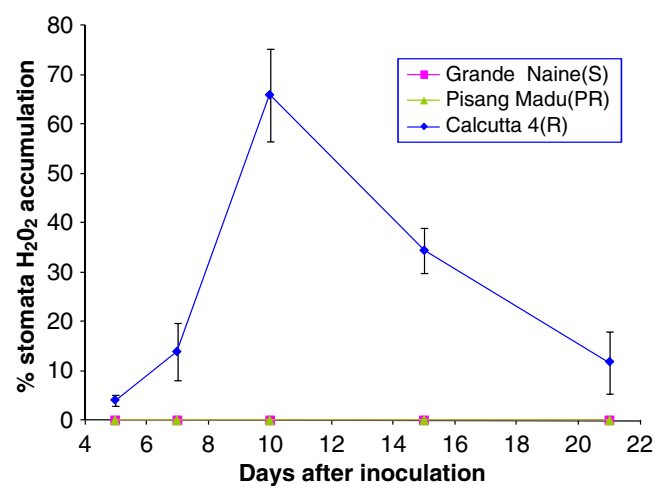

Fig. 5 Percentage of infected stomata stained with DAB, showing significant $\mathrm{H}_{2} \mathrm{O}_{2}$ accumulation in the resistant genotype Calcutta 4

infected site was indicated by quenching of chlorophyll red fluorescence under blue light (Fig. 2c, f and i). The resistant phenotype showed a thickening in stomatal cell walls at the infection site (Fig. 3c) with the smallest necrotic lesion (limited to stomata guard cells and subsidiary cells) surrounded by chlorotic cells.

At $15 \mathrm{DAI}$, the mycelium penetrated and spread intercellularly inside the substomatal cavity of the spongy parenchyma of the Grande Naine genotype (Fig. 3a). Figure $3 \mathrm{~d}$, e, and $\mathrm{f}$ show three views of the same stomata penetrated by the mycelium; the mycelium grew until reaching a mesophyll cell (Fig. 3f).
Histochemical Localization of $\mathrm{H}_{2} \mathrm{O}_{2}$

To reveal $\mathrm{H}_{2} \mathrm{O}_{2}$ production resulting from leaf infection with M. fijiensis, leaves were stained with 3, 3' - diaminobenzidine (DAB) 21 DAI. For Grande Naine and Pisang Madu, the staining was very faint and not restricted to the stomatal zone (Fig. 4a and b). A significant brown stain with DAB was observed in the infected stomata (guard cells and subsidiary cells) for the Calcutta 4 (R) genotype only (Fig. 4c) indicating $\mathrm{H}_{2} \mathrm{O}_{2}$ accumulation in the resistant genotype. Stomata that were not yet infected and epidermis in contact with the mycelium did not react to the $\mathrm{DAB}$ staining. The percent of stomata with $\mathrm{H}_{2} \mathrm{O}_{2}$ accumulation peaked at over $60 \% 10$ DAI and decreased to $10 \%$ of stained stomata 21 DAI (Fig. 5).

\section{Histochemical Localization of Peroxidase Activity}

Peroxidase activity and $\mathrm{H}_{2} \mathrm{O}_{2}$ accumulation showed similar patterns with peak accumulation 10 DAI. A significant difference in peroxidase activity, indicated by a reddishbrown color, occurred only at the cell wall level in the Calcutta 4 (R) genotype in the guard and subsidiary cells and sometimes in the epidermis and in mesophyll cells around the infection site (Fig. 6c, d). This activity was seen throughout the time course of infection peaking $10 \mathrm{DAI}$ (Fig. 7). The number of cells that exhibited peroxidase
Fig. 6 Histochemical localization of peroxidase activity. $(\mathbf{a}, \mathbf{b})$ Absence of peroxidase activity for the Grande Naine (S) and Pisang Madu (PR) genotypes 10 day after inoculation; (c, d) Presence of peroxidase activity around infected stomata in leaves of the Calcutta4 genotype (R), 5 and 10 days after inoculation. (bar $=22 \mu \mathrm{m})$. f: fungal mycelium; mc: mesophyll cell; pox: peroxydase activity; st: stomata
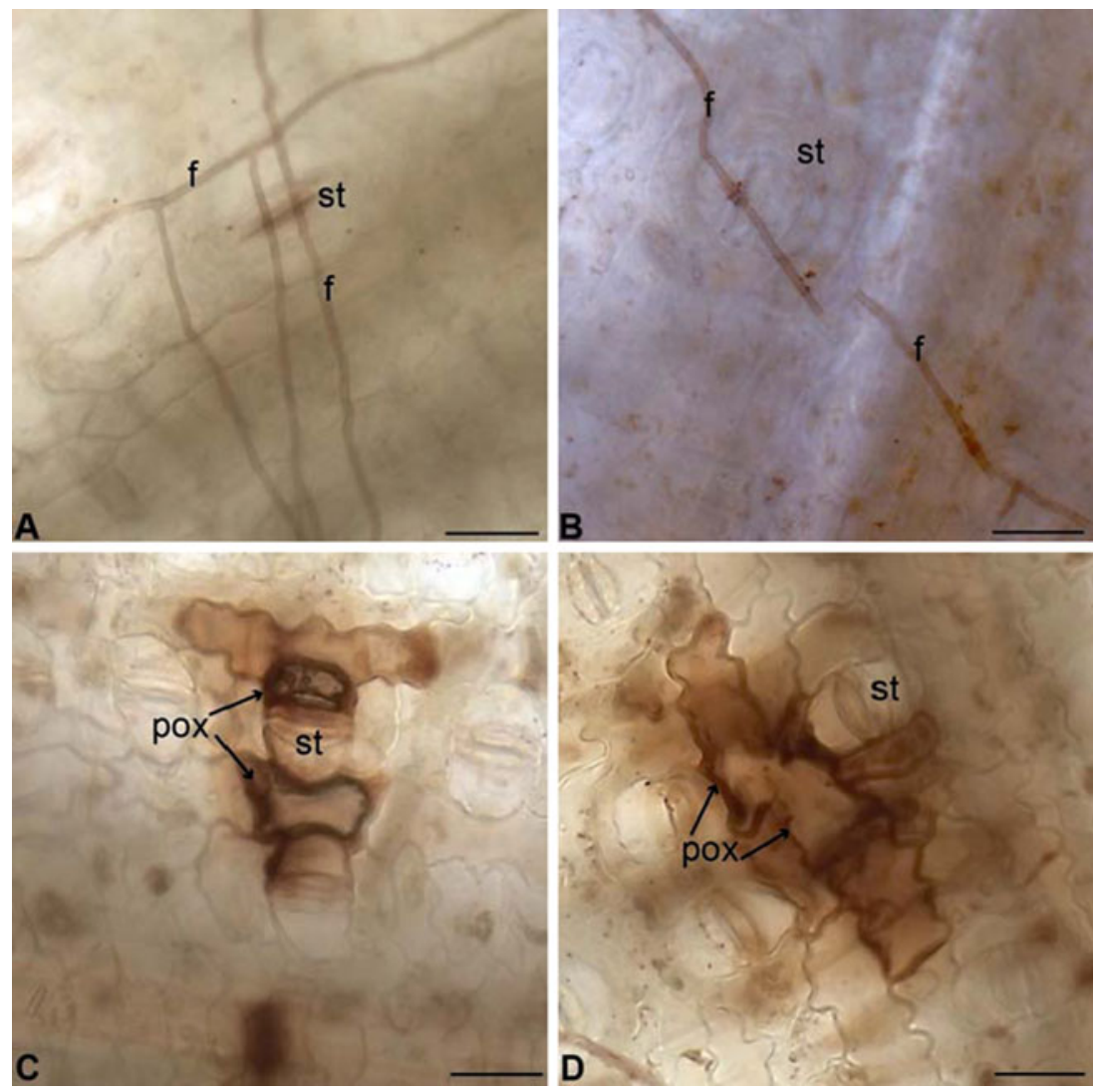


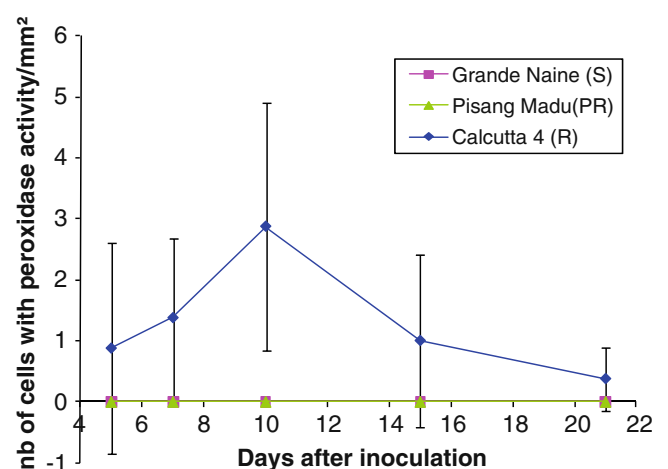

Fig. 7 Peroxidase activity was detected using $\mathrm{H}_{2} \mathrm{O}_{2}$ and DAB during the time course of infection for $M$. fijiensis for the three genotypes Grande Naine (S), Pisang Madu (PR) and Calcutta 4 (R). Averages were calculated from 7 replicates

activity rapidly decreased between 15 and 21 DAI (Fig. 7). No peroxidase activity was detected in samples from neither the Grande Naine (S) (Fig. 6a) nor the Pisang Madu (PR) (Fig. 6b) genotypes.

\section{Discussion}

Despite the economic impact of Black leaf streak disease (BLSD) in banana production, there are few published studies concerning interactions between Mycosphaerella fijiensis and Musa spp. that might indicate host plant defence mechanisms. This lack of published reports may result from the complexity of this hemibiotrophic pathogen. Although the defence mechanisms are poorly documented, they may be attributed to physiological factors taking place after pathogen mycelium penetration of leaf stomata (Beveraggi et al. 1995; Hoss et al. 2000).

In this present study, none of the early infection pattern markers tested (oxidative burst, phenolic compounds or phytoalexine) could be detected during the first 4 DAI. Plant response to the pathogen was observed 5 DAI when the pathogen mycelium invaded the leaf tissue via the stomatal aperture. From 5 DAI onwards, there was a normal sequence of symptoms with clear necrotic lesions visible on day 10 , with chlorosis around the infection site, and conidiophore appearance 25 to 30 DAI for Grande Naine, 30 to 35 DAI for Pisang Madu and only small necrotic spots barely visible to the naked eye for Calcutta 4 at 21 DAI.

Our results suggest that the reaction between M. fijiensis and banana plant cells is slow compared to the response time of other pathosystems. For example wheat $\mathrm{x}$ Mycosphaerella graminicola in which accumulation of $\mathrm{H}_{2} \mathrm{O}_{2}$ increased in the mesophyll beginning 5 DAI (Shetty et al. 2003). For banana, an accumulation of $\mathrm{H}_{2} \mathrm{O}_{2}$ in parallel with an increase in peroxidase activity were observed associated with a HR-like in the resistant Calcutta 4 (R) genotype, supposedly as defence responses against $M$. fijiensis. Both $\mathrm{H}_{2} \mathrm{O}_{2}$ and peroxidase activity peaked 10 DAI apparently inhibiting growth of the fungus thus confirming previous reports (Hoss et al. 2000). The increase in peroxidase activity suggests a potential defense response, either as a mechanism for protecting host cells from ROS damage, or as a ROS-generating mechanism (Abadie et al. 2008; Davies et al. 2006; Ślesak et al. 2007). Similar results have been reported in other pathosystems such as tomato $\mathrm{x}$ Oidium neolycopersici in which a higher increase in peroxidase activity was observed in resistant plants as compared to susceptible plants, an increase which preceded plant cell collapse and a hypersensitivity response (Mlícková et al. 2004). In our time course analysis, $\mathrm{H}_{2} \mathrm{O}_{2}$, peroxidase accumulation and HR-like establishment in the Calcutta 4 genotype took longer, confirming the hypothesis that $M$. acuminata resistance during the incompatible interaction is effective only after fungal penetration of the plant tissues.

Partial resistance (PR) of the Pisang Madu genotype was confirmed by the delay in symptom development (45 DAI instead of the 30-35 DAI) and fewer necrotic spots (data not shown) as compared with the speed for expressing symptoms in the susceptible (S) Grande Naine genotype.

Histochemical tests are performed to characterize molecules, e. g. phenolics that may be associated with partial resistance (Valette et al. 1998). This finding is in contrast with previous studies on the same pathosystem that hypothesized the occurrence of polyphenolic substances in genotypes indicates partial resistance (Beveraggi et al. 1995; Beveraggi 1992; El Hadrami 2000). Although research on other pathosystems, such as Arabidopsis thaliana x Phytophthora infestans (Huitema et al. 2003) and wheat $\mathrm{x} M$. graminicola reported a larger percentage of cells accumulated autofluorescent substances such as phytoalexines (Cohen and Eyal 1993; Shetty et al. 2003), none were observed in our present work. Phenolic patterns in banana did not differ between the susceptible and resistant genotypes. Additional investigations using more accurate techniques such as laser capture micro-dissection associated with mass spectrometry to facilitate isolation of specific reactive infection sites might provide a definitive answer about the role of phenolics since previous chromatographic analysis using whole leaves also failed to identify these compounds (Beveraggi et al. 1995; Beveraggi 1992).

The dark areas observed under UV light and the blue fluorescence around and below infected stomata were largest in Calcutta 4 and Pisang Madu genotypes (Fig. 2e, $\mathrm{f}, \mathrm{h}, \mathrm{i}$ ), in both cases exceeding the size of the lesion as viewed under the microscope with visible light (Fig. 2d, g). According to Hoss et al. 2000, one explanation for this is that natural or synthetic elicitors secreted by the fungus 
may act as toxins at the beginning of the infection in the resistant genotype (Heath 1998; Svabova and Lebeda 2005; Yoder 1980) thus quenching the fluorescence without destroying all the plant cells. Application of a raw extract from $M$. fijiensis suggested that chloroplasts may be a preferred site of action of a toxin produced by the fungus (Harelimana et al. 1997).

An increase in cell wall thickness was observed at infection sites of the Calcutta 4 (R) genotype 10 DAI. This occurrence was weaker in Pisang Madu (PR) and absent in Grande Naine (S) genotype, indicating a close relationship with resistance. Neither callose nor lignin deposition as structural defence barriers were seen after using appropriate histochemical tests (aniline blue and phloroglucinol respectively). According to Huitema (Huitema et al. 2003), cell wall thickening is considered to be a defence response during the hypersensitivity reaction in the Arabidopsis thaliana $\mathrm{x}$ Phytophthora infestans pathosystem. This may explain the early activation of cell wall thickening in the resistant Calcutta 4 (R) genotype as compared to Pisang Madu (PR) the partially resistant genotype (Fig. 3b).

This study revealed multiple insights concerning the defence response of three banana genotypes to $M$. fijiensis infection. The main findings from this study were the failure to detect early plant reactions and the role of $\mathrm{H}_{2} \mathrm{O}_{2}$ and peroxidase activity as important defence mechanisms associated with the hypersensitivity-like reaction shown by the resistant genotype Calcutta 4 (R).

\section{Methods}

Plant and Pathogen Material

\section{Plant Material}

The three banana genotypes used in this study were: Calcutta 4 (R), Pisang Madu (PR), and Grande Naine (S). Banana plants were initially transplanted into $250 \mathrm{ml}$ pots containing an organic-rich substrate and kept in a greenhouse with $80 \%$ relative humidity and temperature ranging from 25 to $28^{\circ} \mathrm{C}$. The photoperiod was $12 \mathrm{~h}$ of fluorescent white light with an intensity varying from 40 to $80 \mathrm{mmol}^{-2} \mathrm{~s}^{-1}$ during a three month period. Plants were watered and fertilized weekly with a solution containing $0.3 \mathrm{gL}^{-1}$ of Algo-Speed Flo 17-7-22 (N-P-K). After three months, the plants were transferred to $5 \mathrm{~L}$ pots containing a mixture of the same organic-rich substrate (45 L), gravel and sand $(10 \mathrm{~L})$ and maintained under the same greenhouse conditions for six more months. In addition to $0.3 \mathrm{~g} \mathrm{~L}^{-1}$ Algo-Speed Flo 17-7-22, a solid fertilizer, $2 \mathrm{~g}$ Osmocote per $5 \mathrm{~L}$ pots (N10 P11 K18), was also applied every 21 days. Insecticide was applied every 30 days to protect young plants from mites ( $2 \mathrm{ml} / \mathrm{l}$ Vertimec, CI 240778 Syngenta A8612A). The plant leaves (youngest leaves counting from the 'cigar' leaf i.e. the uppermost longitudinally curled leaf) used in the experiment were harvested, and inoculated in vitro.

\section{Preparation of the Isolate}

The isolate $\mathrm{n}^{\circ} 139 \mathrm{~A}$ of $M$. fijiensis collected in Columbia, was frozen at $-80^{\circ} \mathrm{C}$ in $15 \%$ glycerol, then thawed and put in $10 \mathrm{~cm}$ diameter Petri dishes containing PDA medium ( $39 \mathrm{~g} / \mathrm{L}$ of agar and potato dextrose) with two antibiotics: $100 \mu \mathrm{g} / \mathrm{ml}$ sulfate of streptomycin (Sigma: S-6501) and $100 \mu \mathrm{g} / \mathrm{ml}$ penicillin (Sigma: PEN-NA). The Petri dishes were maintained for 10 days in a growth chamber at $25^{\circ} \mathrm{C}$ with a $12 \mathrm{~h}$ photoperiod (obtained with one white fluorescent $36 \mathrm{~W}$ light and an ultraviolet light-Grolux 4000). After 10 days, pieces of mycelium were transferred to another culture medium, V8300 $(150 \mathrm{ml} \mathrm{V8} \mathrm{vegetable}$ juice, $1.5 \mathrm{~g} \mathrm{CaCO}_{3}, 10 \mathrm{~g}$ PDA, $350 \mathrm{ml}$ water, $100 \mathrm{UI} / \mathrm{ml}$ penicillin, and $100 \mu \mathrm{g} / \mathrm{ml}$ streptomycin and maintained for 10 more days under the same conditions.

Afterwards pieces of mycelium were macerated in $10 \mathrm{ml}$ water and the mixture was poured into $15 \mathrm{ml}$ plastic test tubes. This infusion was then transferred to V8 culture medium $(2 \mathrm{ml}$ per $9 \mathrm{~cm}$ diameter Petri dish containing V8 (50 ml V8, vegetable juice, $0.1 \mathrm{~g} \mathrm{CaCO}_{3}, 10 \mathrm{~g}$ PDA, $450 \mathrm{ml}$ water and $\mathrm{pH} 6$ and the same antibiotics) to produce spores. The Petri dishes were sealed with parafilm and placed in growth chambers at $20^{\circ} \mathrm{C}$ with continuous (obtained with one white fluorescent $36 \mathrm{~W}$ light and an ultraviolet light - Grolux 4000 at an intensity of 60 $65 \mu \mathrm{mol} . \mathrm{m}^{-2} . \mathrm{s}^{-1}$ ) for 10 to 14 days.

\section{Inoculation of Banana Leaves}

The experimental design was completely random with eight leaf segments from one plant for genotype. The infection kinetics were measured $0,1,4,5,7,10,15$ and $21 \mathrm{DAI}$ with $M$. fijiensis via sampling without replacement: Petri dishes were discarded after sampling. Treatments were genotypes and time of infection (DAI). The inoculation was accomplished in the laboratory using leaves of each genotype. The inoculum was prepared from conidia produced on the surface of the V8 medium. For this preparation, 3-5 $\mathrm{ml}$ sterilized water was added to the dish and the mycelium surface was gently scraped to prevent damage. Yield of conidia was evaluated in a 'Neubauer' chamber and the conidia suspension was adjusted to a concentration of $8 \times 10^{3}$ conidia $/ \mathrm{ml}$.

Two fully expanded leaves (two down from the cigar leaf) from each banana cultivar were cut at the base and then transferred into a water containing recipient. The 
abaxial surface of each leaf was cleaned with a cotton swab dipped in sterile water, then $3 \times 3 \mathrm{~cm}$ leaf pieces were cut and placed abaxial surface up in $55 \mathrm{~mm}$ diameter Petri dishes containing $4 \mathrm{~g}$ PDA, $50 \mathrm{ppm}$ benzimidazol (Sigma réf: B-9131), and 11 water (adapted from (Abadie et al. 2008; Huitema et al. 2003)). The adaxial face of the leaf cutting was in constant contact with the culture medium. Leaves were inoculated on the abaxial leaf surface of each banana genotype via an eyedropper (4 droplets of $1.5 \mu \mathrm{l}$ conidial suspension $(8$ conidia/ $\mu$ l) on the abaxial). Control leaves were treated with 4 droplets of distillated water. Petri dishes were then sealed with parafilm and placed in a growth chamber $\left(25^{\circ} \mathrm{C}\right.$ and a $12 \mathrm{~h}$ photoperiod). Since foliar symptoms are visible with the naked eye three weeks or 21 days after infection, microscopic analysis was done to determine progression at intervals of $0,1,4,5,7,10,15$ and 21 DAI.

\section{Microscopic Observations}

Inoculated and non-inoculated leaf samples from the three genotypes were collected 0 to 21 DAI and used for the microscopic observations.

\section{Conidia Germination at the Leaf Surface}

Samples of inoculated leaf fragments $(1 \mathrm{~cm} \times 1 \mathrm{~cm})$ were studied microscopically to determine the percentage of germination of the conidia 3 DAI with a transmission light microscope (DM 6000 B, LEICA).

\section{Methyl Blue Staining}

All leaf samples (4 replicates per each DAI) were fixed and bleached using a solution of ethanol-chloroform $(4 \mathrm{~V} / 1 \mathrm{~V})$. Samples were kept in a cold chamber for 15-20 days and then transferred to $70 \%$ ethanol. The samples were maintained in $50 \%$ glycerol for two days and then placed in a $2 \mathrm{~cm} \times 3 \mathrm{~cm}$ rectangle delimited by nail varnish on a slide. This slide was pre-heated on a hot plate to $50^{\circ} \mathrm{C}$ for 5 min to evaporate the ethanol, and then covered with a solution of methyl blue $0.5 \%$ (CI 42780 sigma M5528) in a solution of $20 \mathrm{~g}$ lactic acid, $50 \mathrm{~g}$ glycerol, and 1\% SDS in $30 \mathrm{ml}$ water, pre-heated in a water bath to $50^{\circ} \mathrm{C}$. The samples were heated on a hot plate to $50^{\circ} \mathrm{C}$ for $20 \mathrm{~min}$ and afterwards maintained in the dark at room temperature for $24 \mathrm{~h}$. The samples were then placed in an Erlenmeyer flask containing $8 \mathrm{ml}$ glycerol for $30 \mathrm{~min}$ and then mounted on slides with a cover glass in glycerol/lactic acid $(2 \mathrm{~V} / 1 \mathrm{~V})$. The samples were stained for $10 \mathrm{~min}$ with methyl blue $(0,5 \%)$. Observations were made using a light microscope, DMRXA, Leica. Image acquisitions were taken using an image analysis software (Improvision; Openlab), and a numeric camera (Qimaging; Micropublisher 3.3RTV) connected to a computer (Imac; Apple). For higher resolution and higher $3 \mathrm{D}$ image quality, samples were also observed with a scanning confocal laser microscope by spectral deconvolution (ZEISS; 510 Meta).

\section{Histochemical Localization of Callose, Lignin and Other Phenolic Compounds}

Infected leaf samples (4 replicates) were analyzed to verify of callose accumulation using the procedure of Eschrich and Currier (Eschrich and Currier 1964). For this, samples were fixed and bleached in ethanol-chloroform $(4 \mathrm{~V} / 1 \mathrm{~V})$. washed in $50 \%$ ethanol, and then stained with aniline blue WS (CI 42755 Prolabo 21.999.183) for $30 \mathrm{~min}$. The samples were then mounted in a $50 \%$ glycerol and observed with an epifluorescence microscope under UV excitation (DM 6000 B, Filter A; Leica). The presence of callose was indicated by a bright yellow florescence. To visualize lignin deposits, samples were immersed in $10 \%$ phloroglucinol (Sigma ref P3502) dissolved in 95\% ethanol during $10 \mathrm{~min}$ and then mounted in pure $\mathrm{HCl}$ (Riedel de Haën ref 30721). The presence of lignin was indicated by a red coloration (Jensen 1962). For the presence of phenolic compounds, slices obtained with a cryomicrotome (Cryostat Microtome HM 520) were stained with 2-amino-ethyldiphenylborinate (DPBA Fluka ref 42810), with vanillin-HCl (Sigma ref V-2375) and with 4-dimethylaminocinnamaldehyde (DMACA Sigma ref D4506) and analyzed with the same epifluorescence microscope.

\section{Histochemical Localization of $\mathrm{H}_{2} \mathrm{O}_{2}$}

Leaf samples (4 leaf segments from a leaf of a given genotype) were placed in glass Erlenmeyer flasks containing 3, 3'-diaminobenzidine solution (DAB; Sigma ref D8001) (100 mg DAB in $100 \mathrm{ml}$ water and $50 \mu \mathrm{HCl})$ and left in the dark for $8 \mathrm{~h}$ (Thordal-Christensen et al. 1997). Afterwards the samples were fixed in ethanol-chloroform $(4 \mathrm{~V} / 1 \mathrm{~V})$ and maintained in a cold chamber for 15 days. For each DAI, slices were mounted in $50 \%$ glycerol and observed using a light microscope (DM 6000B, Leica), where $\mathrm{H}_{2} \mathrm{O}_{2}$ accumulation and fungus infected stomata were counted. Eight sites were randomly selected on each foliar surface of $3.6 \mathrm{~mm}^{2}$. The presence of $\mathrm{H}_{2} \mathrm{O}_{2}$ was indicated by a brown staining.

\section{Histochemical Localization of Peroxidase}

Leaf fragments $(1 \mathrm{~cm} \times 1 \mathrm{~cm})$ in 4 leaf segments from a leaf of a given genotype were fixed in $4 \%$ paraformaldehyde (Sigma ref P6148) in a phosphate buffer (Sigma refs S-0751, S-9763), $0.1 \mathrm{M} \mathrm{pH} 7.2$ and left at $4{ }^{\circ} \mathrm{C}$ during 
2 h. After fixation, the samples were washed twice in phosphate buffer and left at $4{ }^{\circ} \mathrm{C}$ during $30 \mathrm{~min}$. Afterwards the samples were transferred to $0.05 \mathrm{M}$ Tris- $\mathrm{HCl}$ buffer, $\mathrm{pH}$ 7.6 and $0.15 \mathrm{M} \mathrm{NaCl}$ and then left $10 \mathrm{~min}$ at room temperature. The samples were then incubated at $37^{\circ} \mathrm{C}$ for $12 \mathrm{~h}$ in the following incubation medium pre-heated to $60^{\circ} \mathrm{C}$ for an hour: $15 \mathrm{ml} 0.05 \mathrm{M}$ Tris-HCl buffer $\mathrm{pH}$ 7.6, $0.15 \mathrm{M}$ $\mathrm{NaCl}$ (10 mg DAB 3, 3' diaminobenzidine tetrahydrocloride (sigma ref D5905) ,100 mM 3-amino-1,2,4 triazole (Sigma ref. A8056) to inhibit catalase (Drumm et al. 1970), $3.3 \mathrm{mg}$ sodium pyruvate $2 \mathrm{mM}$ (Sigma ref. P2256) to inhibit endogenous $\mathrm{H}_{2} \mathrm{O}_{2}$ (Fahimi 1969), $15 \mu \mathrm{l} 0.1 \%$ triton X100 (Sigma ref. T8767), and $150 \mu \mathrm{l} 30 \% \mathrm{H}_{2} \mathrm{O}_{2}$ (Sigma ref. $\mathrm{H} 1009)$. Fixed samples were bleached in ethanol/chloroform $(4 \mathrm{v} / 1 \mathrm{v})$ for 7 days. Each DAI, slices were mounted in 50\% glycerol, and then observed using a light microscope (DM 6000B, Leica). Cells stained in dark brown, sign of peroxidase activity were counted. Seven sites were randomly selected on a leaf surface of $1.17 \mathrm{~mm}^{2}$.

\section{Statistical Analysis}

Variables relating to the biology of fungal infection and DAB staining are discrete with a probable Poisson distribution. Data for percentage germination were transformed to arcsine ( $\%$ of germination/100), and tested for normality using the Anderson-Darling procedure in PROC UNIVARIATE NORMAL PLOT of SAS 9.1 (SAS Online$\operatorname{Doc}^{\circledR}$ 9.1.3). When the hypothesis of normality was rejected (Anderson-Darling A-Sq 1.67; $\mathrm{Pr}>\mathrm{A}-\mathrm{Sq}<$ $0.005)$, the NPAR1WAY median procedure was applied. A variable percentage of infected stomata and stained stomata in DAB were transformed to $(\%$ of stomata infected +0.5$) 1 / 2$ and (\% of stained stomata) and then analyzed using a generalized linear model with repeated measures (procedure GLM repeated measures, SAS 9.1) to determine the temporal effect among the variables. The variables were adjusted by linear regressions (procedure REG, SAS 9.1), with time as a fixed variable to determine the linear association with time. Parallelism of lines was conducted to determine which genotype was faster in developing the disease and line elevation analyses were conducted to determine whether or not two straight lines had the same origin (Zar 1999).

In vitro inoculated sample experiments were conducted in triplicates, while experiments on samples with DAB staining were carried out eight times using a complete randomized design.

Acknowledgements The authors wish to thank Dr. J. Carlier and his team (CIRAD-BGPI, Montpellier,France) for providing the fungus isolate and the plants used in this study; Dr. F. F. Laranjeira (Phytopathology-Epidemiology from Embrapa Cassava and Tropical Fruits) for the valuable suggestions in the statistical analysis;
Drs. M. T. Souza Junior (Embrapa Labex Europe) and G. Kema (Wageningen University) for collaboration in providing the plants. The authors also appreciate Dr. C. Klimas's (DePaul University) translation assistance.

\section{References}

Abadie C, Zapater MF, Pignolet L, Carlier J, Mourichon X (2008) Artificial inoculation on plants and banana leaf pieces with Mycosphaerella spp., responsible for Sigatoka leaf spot diseases $=$ Inoculation artificielle sur plants et tissus de feuille de bananier avec Mycosphaerella spp. responsables de la maladie de Sigatoka. Fruits 5:319-323

Atkinson MM (1993) Molecular mechanisms of pathogen recognition by plants. Adv Plant Pathol 10:35-59

Beveraggi A (1992) Etude des interactions hôte-parasite chez des bananiers sensibles et résistants inoculé par Cercospora fijiensis responsables de la maladies des raies noires. Thèse de 3ème cycle, Université de Montpellier II, USTL

Beveraggi A, Mourichon X, Sallé G (1995) Etude comparée des premieres étapes de l'infection chez les bananiers sensibles et résistants infectés par Cercospora fijiensis (Mycosphaerella fijiensis) agent responsable de la maladies des raies noires. Can J Bot 73:1328-1337

Bolwell GP, Davies DR, Gerrish C, Auh C-K, Murphy TM (1998) Comparative biochemistry of the oxidative burst produced by rose and French bean cells reveals two distinct mechanisms. Plant Physiol 116:1379-1385

Carlier J, Lebrun MH, Zapater MF, Dubois C, Mourichon X (1996) Genetic structure of the global population of bananas black leaf streak fungus Mycosphaerella fijiensis. Mol Ecol 5:499-510

Cohen L, Eyal Z (1993) The histology of processes associated with the infection of resistant and susceptible wheat cultivars with Septoria tritici. Plant Pathol 42:737-43

Davies DR, Bindschedler LV, Strickland TS, Bolwell GP (2006) Production of reactive oxygen species in Arabidopsis thaliana cell suspension cultures in response to an elicitor from Fusarium oxysporum: implications for basal resistance. J Exp Bot 57:18171827

Drumm H, Falk H, Moller J, Mohr H (1970) The development of catalase in the mustard seedling. Cytobiologie 2:335-340

El Hadrami A (2000) Caractérisation de la résistance partielle des bananiers à la maladies des raies noires et évaluation de la variabilité de l'agressivité de l'agent causal, Mycosphaerella fijiensis. Thèse d'Université. Faculté Universitaire des Sciences Agronomiques de Genbloux, Belgique

Eschrich W, Currier HB (1964) Identification of callose by its diachrome and fluorochrome reactions stain. Technology 39:303-307

Fahimi HD (1969) Cytochemical localization of peroxidase activity of catalase in rat hepatic microbodies (peroxisomes) J. Cell Biol 43:275-288

Fouré E, Mouliom Pefoura A, Mourichon X (1990) Etude de la sensibilité variétale des bananiers et plantain à Mycosphaerella fijiensis Morelet. Au Cameroun. Caracterisation de la resistance au champ de bananiers appartenant à divers groupes génétiques. Fruits 45:339-345

Fullerton RA (1994) Sigatoka leaf diseases. In: Ploetz RC, Zentmyer GA, Nishijima WT, Rohrbach KG, Ohr HD (eds) Compendium of tropial fruit disease. APS, New York, pp 12-13

Harelimana G, Lepoivre P, Jijakli H, Mourichon X (1997) Use of Mycosphaerella fijiensis toxins for the selection of banana cultivars resistant to Black Leaf Streak. Euphytica 96:125-128 
Hayden HL, Carlier J, Aitken EAB (2003) Genetic structure of Mycosphaerella fijiensis populations from Australia, Papua New Guinea and the Pacific Islands. Plant Pathol 52:703-712

Heath MC (1998) Involvement of reactive oxygen species in the response of resistant (hypersensitive) or susceptible cowpeas to the cowpea rust fungus. New Phytol 138:251-263

Hiraga S, Sasaki K, Ito H, Ohashi Y, Matsui H (2001) A large family of class III plant peroxidases. Plant Cell Physiol 42:462-468

Hoss R, Helbig J, Bochow H (2000) Function of host and fungal metabolites in resistance response of banana and plantain in the black sigatoka disease pathosystem (Musa spp.-Mycosphaerella fijiensis). J Phytopathol 148:387-394

Hückelhoven R, Kogel K-H (2003) Reactive oxygen intermediates in plant microbe interactions: who is who in powdery mildew resistance? Planta 216:891-902

Huitema E, Vleeshouwers VGAA, Francis DM, Kamoun S (2003) Active defence responses associated with non-host resistance of Arabidopsis thaliana to the oomycete pathogen Phytophthora infestans. Mol Plant Pathol 6:487-500

Jensen W (1962) Botanical histochemistry. Freeman \& Company, San Francisco

Jones DR (2000) Introduction to banana, abacá and enset. In: Jones DR (ed) Diseases of banana, abacá and enset. CAB International, Wallingford, pp 1-36

Kiraly L, Barna B, Kiraly Z (2007) Plant resistance to pathogen infection: forms and mechanisms of innate and acquired resistance. J Phytopathol 155:385-396

Marín DH, Romero RA, Guzmán M, Sutton TB (2003) Black sigatoka: an increasing threat to banana cultivation. Plant Dis $87: 208-222$

Mika A, Minibayeva F, Beckett R, Lüthje S (2004) Possible functions of extracellular peroxidases in stress-induced generation and detoxification of active oxygen species. Phytochem Rev 3:173-193

Mlícková K, Luhová L, Lebeda A, Mieslerová B, Pec P (2004) Reactive oxygen species generation and peroxidase activity during Oidium neolycopersici infection on Lycopersicon species. Plant Physiol Biochem 42:753-61
Mourichon X, Carlier J, Fouré E (1997) Sigatoka leaf spot disease, Musa Disease. fact Sheet, Inibap, Montpellier, France, 8:4p

Resende MLV, Salgado SML, Chaves ZM (2003) Especies ativas de oxigênio na resposta de defesa de plantas a patógenos. Fitopatologia Brasileira 28:123-130

Shetty NP, Kristensen BK, Newman M-A, Møller K, Gregersen PL, Jørgensen HJL (2003) Association of hydrogen peroxide with restriction of Septoria tritici in resistant wheat. Physiol Mol Plant Pathol 62:333-346

Shirasu K, Schulze-Lefert P (2000) Regulation of cell death in disease resistance. Plant Mol Biol 44:371-385

Silva SO, Souza MT Jr, Alves EJ, Silveira JRS, Lima MB (2001) Banana breeding program at Embrapa. Crop Breed Appl Biotechnol 4:399-436

Ślesak I, Libik M, Karpinska B, Karpinski S, Miszalski Z (2007) The role of hydrogen peroxide in regulation of plant metabolism and cellular signaling in response to environmental stresses. Acta Biochim Pol 54:39-50

Svabova L, Lebeda A (2005) In vitro selection for improved plant resistance to toxin-producing pathogens. J Phytopathol 153:5264

Thordal-Christensen H, Zhang Z, Wie Y, Collinge D (1997) Subcellular localization of $\mathrm{H} 2 \mathrm{O} 2$ in plants. $\mathrm{H} 2 \mathrm{O} 2$ accumulation in papillae and hypersensitive response during the barleypowdery mildew interaction. Plant J 11:1187-94

Valette C, Andary C, Geiger JP, Sarah JL, Nicole M (1998) Histochemical and cytochemical investigations of phenols in roots of banana infected by the burrowing nematode Radopholus similis. Phytopathology 88:1141-1148

Wang CF, Huang L, Buchenauer H, Han QM, Zhang HC, Kang ZS (2007) Histochemical studies on the accumulation of reactive oxygen species (O2 and $\left.\mathrm{H}_{2} \mathrm{O} 2\right)$ in the incompatible and compatible interaction of wheat-Puccinia striiformis f. sp. tritici. Physiol Mol Plant Pathol 71:230-239

Yoder OC (1980) Toxins in pathogenesis. Ann Rev Phytopathol 18:103-129

Zar JH (1999) Biostatistical analysis, 4 edn. New Jersey 